Review Article

\title{
A Literature Review on Routing Strategy in the Internet of Things
}

\author{
Ravi Kumar Poluru and Shaik Naseera*
}

School of Computer Science and Engineering,VIT University, Vellore, Tamilnadu, India

Received 22 May 2017; Accepted 20 September 2017

\begin{abstract}
Recently Internet of Things (IoT) has gain popularity as the number of smart devices being used in day to day human life having network lifetime as a constraint. In providing connectivity between nodes, passing of routing information plays a prominent role. We identified that maximum energy of smart devices is utilised in routing the data (or) control packets. The objective of our research is to address the gaps in optimizing the network usage, which in turn maximize the network lifetime. In these directions, so far the literature review made on scalability, energy efficiency, Quality of Service (QoS), network lifetime, node deployment with Wireless Sensor Networks (WSN) perspective. In the present work we made a systematic review addressing the challenges and issues in routing with IoT perspective from the year 2014 to 2017. Additionally, we compare the performance of the routing protocols using measures like latency, bandwidth, jitter, delay.
\end{abstract}

Keywords: Internet of Things (IoT), Routing, Wireless Sensor Networks (WSN), Scalability, QoS, Communication.

\section{Introduction}

In recent years the utilization of internet has been reached to 3 billion people based on survey generated by United Nations agency [1]. The Auto-ID Center is a research organization which term Internet of Things (IoT) in a decade back, where it uses wired or wireless communication technologies to establish a communication channel between devices and services available over the Internet [2 - 3]. The IoT devices are embedded with a rich set of processing, sensing and networking capabilities to achieve some useful objective [4]. In IoT, devices consist of intrinsic as an actuator, sensors, Radio Frequency IDentification (RFID), and communication interfaces such as Global Positioning devices (GPS), infrared, Bluetooth, Wireless LANs [5]. The IoT devices are connected each other to transmit information using an inter transfer protocol. This connectivity helps us to capture more amounts of data from more areas. IoT is a platform that is serving as a bridge between device sensors and the data networks.

As per the Gartner, projects more than 20.8 billion smart devices are going to interconnect to the cyberspace by 2020 [6]. As per the Cisco, 50 billion smart devices will associated to WWW by 2020 [7]. IoT has been used in different applications such as smart home, smart grid, smart agriculture, smart city, etc. The exponential growth of IoT devices suffers from adopting various standards and technologies. The other serious issue in IoT devices is interoperability among communication devices and services. The communication devices should be flexible in adopting the situation in carrying information with less human

\footnotetext{
*E-mail address: shaik.naseera@vit.ac.in

ISSN: $1791-2377 @ 2017$ Eastern Macedonia and Thrace Institute of Technology. All rights reserved. doi:10.25103/jestr.105.06
}

involvement [8]. The human free and human-centric are two kinds of a pervasive paradigm based on human interaction. IoT is a jumbled collection technology which works together with one after the other it does not depend on a single technology [9].

The communication between devices in IoT done with the help of wireless networks. In IoT, the interaction between devices done by using sensors and actuators. An actuator is used to maintain the change in the environment of a device. A sensor is used to collect, store and process the data. In IoT, the processed data sent to a remote server where a remote server is used to store and process the data. Sometimes the storage and processing will be restricted to some available resources due to the limitations of size, energy consumption and computational capability of an IoT objects.

Routing is playing a vital role in IoT devices. Routing is a very challenging aspect that takes place in IoT because of its intrinsic properties. Sometimes routing protocol called as routing policy, which specifies how routing devices communicate with each other in the network, circulating control information that to select best routes between any two nodes among multiple routes. In routing protocol information (or) data can be shared from a source node through nearest neighbors and reaches to the sink node. Based upon algorithms in routing it decide the best path between the source and the destination node. Different authors implemented different algorithms and protocols to increase the lifetime of the network, efficiency in routing.

The objective of this paper is to provide the reader a comprehensive discussion of the literature review on routing in IoT. The paper is organized as follows. In Section 2, we discussed routing issues and challenges in IoT. In Section 3, we discussed Routing Protocols in IoT. In Section 4 discussed multipath routing protocols in IoT. Section 5 
Presents an energy efficient routing protocols in IoT. Finally, Section 6 concludes the paper.

\section{Routing Issues and Challenges In IoT}

Many challenging factors mold the design of routing protocols in IoT. A few of them are explained as follows in this section [10]:

a) Context Awareness: In IoT, all the devices act like actors. For fast routing, it is important to collect the context of the environment and examine it for generating knowledge. This knowledge used for making routing decisions.

b) Heterogeneity: IoT is a platform which helps in bringing various technologies together. As there are so many technologies, the heterogeneity will be regarding devices, and their networking standards Heterogeneity includes additional complexity in the routing process. The protocols which are existing now have rigid boundaries. So it is mandatory to build a routing protocol that can incorporate all types of heterogeneity in it.

c) Death of nodes: A network may contain many nodes which are energy constrained due to over usage of energy it results in the death of a node. It is complex to exchange the batteries of nodes every time. Due to dead nodes, energy holes created which may create short jumps in the routing process as the controlling devices have short ranges.

d) Topology changes: There are so many different reasons for network topology changes such as constant mobility of nodes, complete energy enervation of nodes and some other environmental factors. To overcome this problem we need to develop a reactive or hybrid routing protocol which helps in frequent topology changes in the network.

e) Scalability: Almost all IoT involves in wireless communications. The devices using these technologies may be stationary or mobile. The mobile devices sometimes enter or leave the network, which tends to increase or decrease the size of the network, and thus the network scalability can affect the routing.

f) Latency: The data which generated in IoT will get expired within some span of time, but it is necessary to send the data to the destination within time stipulated. It is very important to handle the latency of routing protocols to maintain quality services.

g) Incentive Based Routing: Cooperation held between they do communication between devices. As IoT has so many number devices, it is necessary to make every device to communicate with each other to make routing successful.

h) Congestion control: Congestion control is a problem which normally occurs in all types of networks. It takes place in because of the rapid increase in traffic which is a complex phenomenon. Packet loss and unwanted delays are the results of congestion. To protest the congestion load balancing should be done at every node. Congestion reduces the lifetime of a network. So it is essential that routing protocol should try to overcome congestion.

i) Data security: As the data transmitted within various networks possess different owners, so it is necessary to secure the whole data. As everything transmitted through wireless in IoT, it is straightforward to sleuth the data. For preventing the data theft, Authentication is necessary before making the connection between two devices.

j) Elimination of data redundancies: IoT networks will send a large amount of data to the destination for processing. So instead of exchanging some data continuously and wasting of networks energy; it is necessary to process data Coalition for reducing the data redundancies.

k) Multipath routing: It is important to perform load balancing and also to Increase the network lifetime. Not only load balancing, but Multipath routing also helps in increasing the Fault Tolerance, Reliability, and Quality of Services.

1) Limited Resource: One of the most significant challenges to IoT is the limitation of resources, which includes energy supply, processing power, memory capacities, wireless communication range and wireless communication bandwidth. This limitation will affect routing in many ways. The short wireless communication range explains that routing must do in a multihop fashion, i.e., the data packets need to be forwarded by multiple relay nodes to reach their final destination. Deficient processing power and program memory require the routing process that is running on IoT devices must be highly optimized and light weight. Small storage memory and limited communication bandwidth should limit the size of packets that need to forward. The limited energy source will make it very difficult to approve which node must forward the data, packets just because of this the wireless communication reign the power consumption of the IoT devices.

m)Node Deployment: It could be a basic issue to be resolved in IoT. The complexity of the issue in IoT can be addressed by placing the node deployment properly in sensor networks. For instance, communication, routing, etc. Based upon the application in IoT, the node deployment consists of setup or manual. In manual, the sensor nodes will be arranged manually, and the path will be predetermined to send the data. In setup, the sensor nodes will be arranged randomly with the help of adhoc routing infrastructure.

\section{Routing Protocols in IoT}

In IoT, the devices are mainly interacting with each other from source to target devices which will process, store and analysis the information. Efficient protocols must support for transmitting the data between the devices concerning low energy consumption and scalability [11]. Routing is denoted as the process of moving the packets of data from end-to-end which tends to maintain route between devices in wireless networks. Routing always needs to choose best or shortest path to reach the destination, and it needs to make use of protocols to accomplish source to destination. Communication can obtain by using either intradomain network or interdomain network [12].

In IoT, routing protocols classified into three types based upon wireless communications. They are 1. Network Organization 2. Route Discovery and 3. Protocol Operation. In Figure. 1 showing the taxonomy of routing protocols in IoT. 


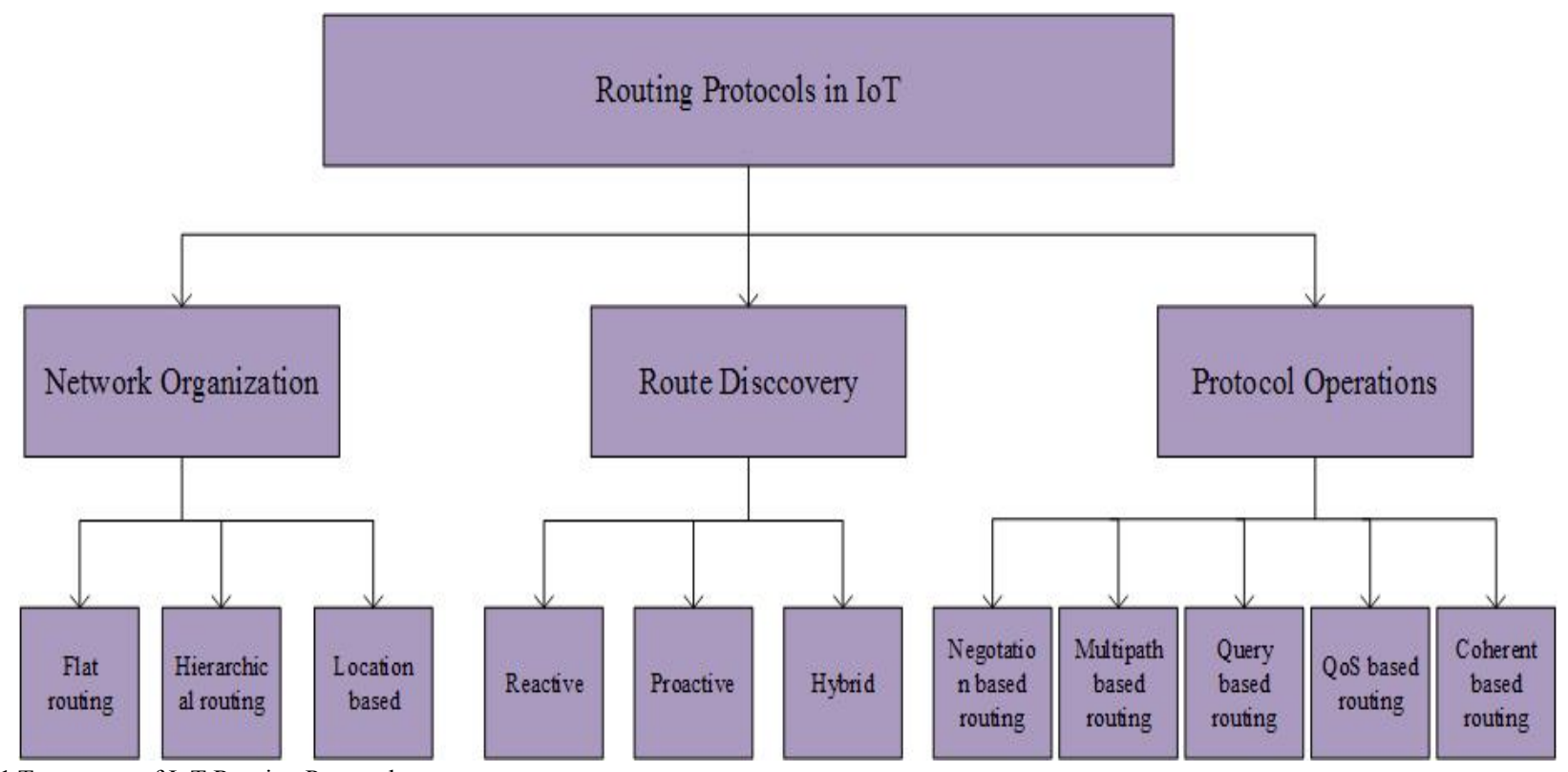

Fig. 1 Taxonomy of IoT Routing Protocols

\subsection{Network Organization}

In IoT, the network organization plays a crucial aspects in the activity of routing protocols. This network organization gives a brief description of the features of a network. The different protocols involving in a network structure are explained below such as:

\subsubsection{Flat-based routing}

This is also known as Horizontal routing. This kind of protocols is used in the network having flat or horizontal structure. All nodes in this network are treated evenly, and they consist of the same functionality. Here there is no need to take any efforts to organize the network and its traffic. Flat-based routing is a contention-based scheduling. In IoT, this network is used to give a suitable a solution for many independent problems which occur due to their low operational complexity and high efficiency. This Flat-based routing is again classified into different types there are SPIN, Directed Diffusion, Rumor Routing, MCFA, COUGAR, ACQUIRE, Gradient-based routing and others [13-16].

a) Sensor Protocol for Information via Negotiation (SPIN ): In this algorithm [13] tends to divide the existing data into meta data and sends it to neighboring nodes to avoid redundant data transmission. It sends the data and requests for a valid data without any destruction. SPIN increases the network lifetime through energy consumption.

b) Directed Diffusion (DD): In this algorithm [14], the query will be sent continuously to the neighboring nodes from Base Station (BS). Once after receiving the query from $\mathrm{BS}$ the node containing the desired data transmit it all the way back to BS. Here energy consumption is done by selecting the optimal return path.

c) Rumor Routing (RR): RR [15] is a variation of Directed Diffusion. In RR, it will compare both number of events and queries. It the events are less than queries then the technique used as flooding the events. RR will use Agents in network which flood the events. Agents travel from one event to another event. Agents stores information in event table. RR algorithm helps in minimizing the cost of communication and energy consumption.

d) Minimum Cost Forwarding Algorithm (MCFA): In this algorithm [16], the nodes present in the network knows the least cost path within itself and a base-station. Here least cost path is obtained through initialization. Now the node checks whether the arrived information estimation is less than or more than the current message. If the received message is less than the current message then both the messages are updated. MCFA is useful for small networks rather than bigger networks. In this algorithm, energy consumption is done by selecting the optimal return paths.

In the view of summarizing the flat based routing protocol, we are highlighting the advantages and performance issues of protocols that include flat routing. Based on the performance issues Rumor Routing is suitable routing protocol compared to SPIN, DD, MCFA because of its excellent scalability, low cost of communication and reduced energy consumption. Rumor routing will handle nodes failure.

\subsubsection{Hierarchical Based Routing}

In this routing, the network topology is differentiated into many layers of hierarchy like clusters and cluster heads based on their energy levels, to reduce the size of the routing table. In hierarchical, if the node contains highest energy are used for sending the data, and whichever node contains lower energy are used for sensing the data. Hierarchical algorithms are Two Layer routing, i.e., Tree Based algorithm and Cluster Based Algorithm.

\subsubsection{Tree-based algorithms}

It will ensure the devices that proportion the same target. The traffic pattern is predicted by constructing a tree based on communication messages between IoT devices [11]. Tree-based algorithms are:

1. WSTDO [20]

2. ETSP [21]

3. LBT [21] 


\subsubsection{Cluster-based algorithms}

In this algorithm, the sensors are split into groups based on the hierarchical model. Based upon the levels in the hierarchical model, the sensor node will perform distinct aspect. The sensor node which contains the highest value in a group will be selected as a cluster head $(\mathrm{CH})$. The main responsibility of $\mathrm{CH}$ is to communicate the information gained within its group and transmit to the another group or base station. In cluster based algorithm the main drawback is a selection of cluster head requires more time. Cluster-based algorithms are:

\section{Low Energy Adaptive Clustering Hierarchy (LEACH) \\ 2. Hierarchical Cost Effective LEACH (HCEL) [22] \\ 3. Advanced-Multi-hop LEACH [23] \\ 4. Stable Election Protocol (SEP) [24] \\ 5. Distributed Energy Efficient Clustering Algorithm (DEEC) [25] \\ 6. Self-Organized Clustering-M2M (SOC-M2M) [26]}

a) Low Energy Adaptive Clustering Hierarchy (LEACH): LEACH [41] consists of low energy consumption and increases the life time of network. In LEACH sensors are placed randomly where base station is placed at fixed infrastructure. LEACH is an self configured. LEACH consist of two phases. In first phase i.e. setup phase it will form as cluster and elected as cluster head $(\mathrm{CH})$ which contains highest energy. In second phase i.e. stable phase transimitting of data takes place from actual data to base station. By using TDMA protocol it will avoid the collisions in LEACH.

b) Self Organizing Protocol (SOP): SOP [55] contains sensors like mobile sensors or stationary sensors. Mobile sensors are used to sense the information, process and finally forward the processed data to group of nodes. Stationary sensors called as routers, these routers will act like backbone for communication.

c) Virtual Grid Architecture (VGA): VGA [55] contains symmetric and non-overlapping clusters with reduced cluster heads. VGA performs Local and global data aggregation. This algorithm uses NP-hard problem to find optimal global aggregators.

d) TEEN and APTEEN: TEEN [17] is used for wireless communication applications where time is crucial. In TEEN sensor nodes continuously sense the information from the physical world but data transmission is very less. APTEEN [18] acts as a hybrid protocol which helps in changing the threshold values of the TEEN protocol as per the user needs. In APTEEN, the cluster-heads produces different parameters given as follows:

- Attributes (A): Attributes are the set of physical parameters through which the user gets the information needed

- Thresholds: Threshold is a parameter that contains both Soft and Hard Threshold.

- Schedule: Schedule contains Time Division Multiple Access, assigning a schedule to individual node.

- Count Time (CT): If the two periods are sequential then $\mathrm{CT}$ will maximizes

In the view of summarizing the hierarchical routing based on the performance issues, we summarize that VGA is best routing protocol based on its excellent scalability and data delivery model and maintains multipath when compared to LEACH, SOP, TEEN, and APTEEN.

\subsubsection{Location Based Routing}

In this routing location of sensor nodes are determined, the signal strength of a node is used to ascertain the location of the node when the nodes are in proximity. The relative coordinates and distance separated by a node are notified with the help of information exchanged between neighboring nodes. In this sensor region, based on the region and position of the neighbor nodes it will establish the transmission route. Location Based Routing is again of different types of routing algorithms they are: Geographic Adaptive Fidelity (GAF), SPAN, Greedy Other Adoptive Face Routing (GOAFR), GEAR.

a) GAF: In GAF [56] routing protocol the structure is partitioned into some area (or) zones. In this zones, only a single node will be awake, and the others will sleep. Here this protocol conserves energy by turning off the nodes which are not useful. GAF is used to increase the network lifetime.

b) SPAN: In this protocol [19], few sensor nodes are taken as coordinators based upon positions. It considers the coordinators only to some extent like up to the network is three hops reachable. It does not possess efficient energy when compared to others.

In Location routing, we summarize the protocols based on its performance issues. When compared to SPAN, GAF has excellent scalability, so it is considered as best routing than SPAN.

The below specified hierarchical, flat and location based protocols are distinct in many conditions. We tend to analyze the hierarchical and flat based routing as presented in Table 1.

Table 1 Comparison between Hierarchical, flat structure and location based routing

\begin{tabular}{|c|c|c|}
\hline Hierarchical structure & Flat structure & Location based routing \\
\hline $\begin{array}{llll}\text { In hierarchical scheduling } & \text { based } \\
\text { reservation }\end{array}$ & In flat scheduling based on contention & $\begin{array}{l}\text { In location based schedulin } \\
\text { on location }\end{array}$ \\
\hline $\begin{array}{l}\text { In hierarchical collisions can be easily } \\
\text { avoided }\end{array}$ & In flat collisions occurred & tion based collisions can be \\
\hline $\begin{array}{l}\text { In hierarchical based on sleeping the nodes } \\
\text { the duty cycle can be reduce } \\
\text { Routing is an non optimal }\end{array}$ & $\begin{array}{l}\text { In } \mathrm{fl} \\
\text { and }\end{array}$ & $\begin{array}{l}\text { In location based the nodes will } \\
\text { sleep when it is idle } \\
\text { In location based the routing is }\end{array}$ \\
\hline
\end{tabular}




\begin{tabular}{|c|c|c|}
\hline In hierarchical fairness is guaranteed & In flat fairness is not guaranteed & $\begin{array}{l}\text { optimal } \\
\text { In location based fairness may be } \\
\text { guaranteed }\end{array}$ \\
\hline $\begin{array}{l}\text { In hierarchical data aggregation is done by } \\
\text { cluster head }\end{array}$ & $\begin{array}{l}\text { In flat data aggregation is done by } \\
\text { neighbors }\end{array}$ & $\begin{array}{l}\text { In location based data aggregation } \\
\text { is done by clustering }\end{array}$ \\
\hline $\begin{array}{l}\text { In hierarchical local synchronization and } \\
\text { global synchronization is required }\end{array}$ & In flat synchronization is not required & $\begin{array}{l}\text { In location based synchronization is } \\
\text { required }\end{array}$ \\
\hline
\end{tabular}

\subsection{Route Discovery}

Route discovery is nothing but maintaining the routing information from origin to target. It consists of a reactive, proactive protocol and hybrid protocol (combination of reactive and proactive protocols).

\subsubsection{Reactive protocol}

Reactive routing protocol does not contain any information about the nodes and the routes that are formed. Most probably this kind of reactive routing is used in dynamic networks which support continuous changes in topology. Every time IoT supports dynamic topologies so that this reactive routing has a special effect in it. These Reactive routing protocols can be divided into AODV, AOMDV, TORA, SEER, LOADng, TEEN.

a) AODV: AODV [59] is very simple routing protocol and known for its effectiveness and efficiency. AODV permits the construction of routes to appropriate destinations, but AODV avoids it does not matter for the nodes to keep these routes when there is no active communication. In AODV, Loop Free issue will be resolve by adding the sequence numbers in destination. AODV consists of three different message types. Route discovery will be performed by Route Request. Final routes will be decided by Route Replies. Link breakage error messages are warned by Route Errors in an active route in a network. A routing table should be maintained in AODV to keep all the information about the routes even if they are short lived routes.

b) TORA: Temporarily ordered routing algorithm [57] be an on-demand routing protocol. The purpose of TORA is to restrict the control message. TORA use the algorithm called link reversal. TORA consists of three operations first it will create a routing between source to sink node, second it will erase the route when it is invalid between two nodes and finally it will maintain the route if the route will fails then it will assign alternative route to reach to the destination. TORA, when rooted at the destination, tries to build a Directed Acyclic Graph (DAG).

c) SEER: Spectrum and Energy Efficient routing protocol [58] is used in sensor networks to increase the lifetime of network. The advantage of this protocol is scalability. Distance calculation and residual energy avaiable in sink node the route decision will be done. In SEER the energy efficiency is high.

In the view of summarizing the reactive routing protocol SEER protocol will reduce the power consumption and having excellent scalability compare to AODV and TORA. TORA is mainly used in large scale networks.

\subsubsection{Proactive protocol}

Proactive protocols are mostly used in static networks where the topology cannot be changed more than one time. This proactive protocol maintains information in a tabular format which can be called as a routing table. Proactive protocols known as "Table-driven protocols", because routing will be based on routing table. This proactive protocol is again of different forms like LEACH, GEAR, OLSR, DSDV, RPL, GPSR.

a) OLSR: Optimized link sate protocol (OLSR) [62] is successor of algorithm of link state. To maintain a proper topology of the network at each and every node, it involves in exchanging messages periodically. OLSR optimized by Multipoint Relay flooding and Messaging because of minimizing the packet size and retransmissions. OLSR provides optimal routes regarding a number of hops.

b) GPSR: Greedy Perimeter Stateless Routing (GPSR) [60] permits a node towards transmit messages to their closest neighbor who also needs to be closer to the destination to which the information is supposed to travel. A node wants to remember the location of neighbor within a single-hop. Greedy forwarding is an algorithm which is used to calculate the path of nodes and send the data to sink node. In GPSR routing decisions are made dynamically. GPSR consists of Distance vector, path vector and finally link state routing algorithm.

In the view of summarizing the proactive routing protocol, GPSR protocol consists of good perfomance, and low overhead compares to OLSR.

\subsubsection{Hybrid Protocol}

It possesses the same functionalities that proactive and reactive protocols. Hybrid routing is again divided into different routing protocols like Zone Routing Protocol (ZRP), SOC-M2M, OLSR, and others.

a) ZRP: ZRP [61] is an hybrid protocol. The main use of ZRP is data transmission is very fast and minimizes the overhead. ZRP wont transmission to entire network. Zone radius will specify the distances between the nodes. ZRP consists of two types of zones there are Intra and Inter zone routing protocol. Intra zone will works within the routing zones and inter zone will works among routing zones. Most probably it chooses the best part of proactive routing or Reactive routing.

b) SOC-M2M: M2M sensor nodes [26] act as building blocks for IoT. The main purpose of using this protocol to reduce the energy consumption and increase the lifetime of network. SOC-M2M is an self organizing i.e. automatically it will form as clusters and it will elect as cluster head. In this technique each node will share there balance energy to the neighbor nodes.

In the view of summarizing the hybrid routing protocol, a SOC-M2M efficient routing protocol for energy compare to ZRP. 


\subsection{Protocol Operation}

It gives a brief description of the main operational characteristics of routing protocols like communication pattern, hierarchy, delivering methods, computation. This protocol operation are listed below:

\subsubsection{Query Based Routing}

This protocol performs route discovery in two phases: Request phase and Reply phase. Query phase will transmit the data from origin to destination. This query phase generates a query packet and transmit to nearest nodes when any node receives the query it responds it with a reply.

\subsubsection{Negotiation Based Routing}

This routing will rejecting the surplus data occurred between source and the destination. Based on availability of resources negotiation decisions will be occurred

\subsubsection{Context Aware Routing}

Context is nothing, but it can be any information from the environment which will be purposed to describe the entity. The context consists of internal position and external position; the information can be retrieved from sensor nodes, or from the environment, or based on information received from neighbor nodes. In sensor nodes the context which means the status of the battery, speed of the mobility devices, location where it is located, the capacity of memory and processing power. In context, the information received from neighbor node contains source, priority, deadline of the delivery and destination [28]. In environmental context comprises calculate the distance between nodes, network topology, and packet loss ratio.

\subsubsection{Swarm Intelligence Routing}

Ant colony optimization (ACO) is a subversion of the swarm intelligence based algorithm. ACO is a distributed or scattered in nature, and the nodes contain self-organized like birds, swarms of bees, ant colonies and flocks of fishes [29]. In ACO the fundamental assumptions in routing algorithms involves [30], [31] the consecutive steps

1) Stigmergy: In this technique, ants modify discovered paths locally and follow the modified path thus it will form a global coordination between themselves.

2) Foraging: In this technique, ants find the optimal path from the ant colonies to food origin. Foraging is used to find path learning and discovery of food source from the nest.

\subsubsection{Stochastic/probabilistic Algorithm}

Optimization is the main objectives in stochastic algorithms. The purpose of this algorithm is to calculate the routing probabilities to get enhanced network resources like error rate and energy consumption etc. There are two approaches for optimization such as 1 . Real-time optimization and 2. A priori optimization [32].

\section{Characteristics of Stochastic Algorithms [33]:}

1. Implementation is straightforward

2. It is best solutions for the hard optimization problem.

3. Compare to traditional approaches, the development time in the stochastic algorithm is very less.

4. It is robust.

\section{Multipath routing protocol}

This protocol organizes a undeviated communication to get load balancing and also to improve the quality of service. It contains fault tolerance mechanism. Based on this the protocols construct a large number of paths and checks for the energy requirements of a single path for sending periodic messages through that path. The challenges are to achieve reliability, maximum network lifetime, and delay. In single path the network traffic congestion occured. To reduce the network congestion and maximize the performance of the network in routing protocols mutlipath is used. In multipath routing will use alternative paths to reach the destination. Some of the mutipath routing protocols in IoT are discussed below:

a) Ad-hoc on demand Multipath Distance Vector (AOMDV)

AOMDV is an advance version from AODV to resolve the issues in the multipath routing protocol. Compare to AODV the performance is high in AOMDV [34]. In AOMDV, discovering the route is based upon node disjoint paths and link disjoint paths. The link disjoint path is highly used due to node disjoint paths are more strict. AOMDV each node consists of two tables such as routing table and internet connection table (ICT) [35]. In AOMDV it uses the control messages such as sending a request to the destination node via Route Request Message (RREQ) and replying message via Route Reply Message (RREP), checking errors in that path via Route Error Message (RERR) and checking whether the route is alive or not via Hello message. AOMDV achieves better performance compared with AODV.

\section{b) Destination Sequence Distance Vector (DSDV)}

In DSDV protocol [36] which helps in transmitting the data from initial node to destination node. Each node contains routing table information such as sequence number, destination address and a number of hops. Whenever new data is available, the node will immediately update information to another node and maintaining the consistency of routing table.

\section{c) Hybrid Energy Efficient Distributed Clustering} (HEED)

HEED is used to reduce energy consumption [37]. In HEED selecting the cluster head based upon residual energy. Due to nodes are not aware of the locations, the HEED act in partially static and providing equal importance to all nodes. HEED protocol helps in enlarging the time span of the network.

\section{d) Low Energy Adaptive Clustering Hierarchy} (LEACH)

In IoT applications the parameters are used as ease of deployment, network lifetime, latency, quality. This kind of suitable protocols can be designed by using a protocol called as LEACH [38]. LEACH is a proactive routing protocol [39]. The LEACH protocol is a hierarchical protocol [40], [41]. This LEACH protocol includes two phases. The setup (or) configuration phase occurs when clusters are formed, and based on high energy in nodes it will elect as cluster head $(\mathrm{CH})$. The steady phase admits in sending the $\mathrm{CH}$ information to the destination (or) sink. We can find whether each sensor node becomes a Cluster head 
through stochastic algorithms. Single hop routing is exist in LEACH protocol. Each and every time single node will become an $\mathrm{CH}$. In $\mathrm{LEACH}$, low energy consumption and maximize the network lifetime will occur when $\mathrm{CH}$ rotates constantly.

\section{e) Geographic and Energy Aware Routing (GEAR)}

GEAR [27] is used in wireless communication. GEAR is based on location aware and energy. GEAR packets are mainly addressed for locality. In GEAR, each node know they location, residual energy and neighbor status like location and energy through a control message. The links are bidirectional between nodes. In GEAR every node will calculate the learned cost and estimated cost.

In table 2 represents various routing protocols fit under distinct classification and furthermore contrast unique steering methods concurring with numerous measurements.

Table 2 Classification and comparison of IoT routing protocols

\begin{tabular}{|c|c|c|c|c|c|c|c|c|c|c|c|c|c|}
\hline $\begin{array}{l}\text { Routing } \\
\text { Protocols }\end{array}$ & $\begin{array}{l}\text { Classificatio } \\
\mathrm{n}\end{array}$ & $\begin{array}{l}\text { Overhea } \\
\text { d }\end{array}$ & $\begin{array}{l}\text { Quer } \\
\text { y } \\
\text { based }\end{array}$ & $\begin{array}{c}\text { Power } \\
\text { Usage }\end{array}$ & $\begin{array}{l}\text { Mobilit } \\
\text { y }\end{array}$ & QoS & $\begin{array}{l}\text { Data } \\
\text { delivery } \\
\text { Model }\end{array}$ & $\begin{array}{l}\text { Position } \\
\text { Awarene } \\
\text { ss }\end{array}$ & $\begin{array}{l}\text { Negotiatio } \\
\text { n based }\end{array}$ & $\begin{array}{l}\text { Data } \\
\text { aggregatio } \\
\text { n }\end{array}$ & $\begin{array}{l}\text { Localizatio } \\
\text { n }\end{array}$ & $\begin{array}{l}\text { Scalabilit } \\
\text { y }\end{array}$ & $\begin{array}{l}\text { Multipat } \\
\text { h }\end{array}$ \\
\hline $\begin{array}{l}\text { SPIN } \\
{[13]}\end{array}$ & Flat & Low & $\sqrt{ }$ & $\begin{array}{l}\text { Limite } \\
\text { d }\end{array}$ & $\begin{array}{l}\text { Possibl } \\
\text { e }\end{array}$ & $x$ & $\begin{array}{l}\text { Event } \\
\text { Driven }\end{array}$ & $x$ & $\checkmark$ & $\sqrt{ }$ & $x$ & Limited & $\checkmark$ \\
\hline EAR & Flat & Low & $\checkmark$ & N/A & $\begin{array}{l}\text { Limite } \\
\mathrm{d} \\
\text { Limite }\end{array}$ & $x$ & $\begin{array}{l}\text { Demand } \\
\text { Driven } \\
\text { Demand }\end{array}$ & $x$ & $x$ & $x$ & $x$ & Limited & $x$ \\
\hline $\begin{array}{l}\text { GBR } \\
\text { ACQUIR }\end{array}$ & Flat & Low & $\checkmark$ & N/A & $\begin{array}{l}\text { d } \\
\text { Limite }\end{array}$ & $x$ & $\begin{array}{l}\text { Driven } \\
\text { Demand }\end{array}$ & $x$ & $x$ & $\checkmark$ & $x$ & Limited & $x$ \\
\hline & Flat & Low & $\sqrt{ }$ & N/A & & $x$ & Driven & $x$ & $x$ & $\checkmark$ & $x$ & Limited & $x$ \\
\hline [16] & Flat & Low & $x$ & N/A & No & $x$ & Driven & $x$ & $x$ & $x$ & $x$ & Good & $x$ \\
\hline DD [14] & Flat & Low & $\checkmark$ & $\begin{array}{l}\text { Limite } \\
\text { d } \\
\text { Limite }\end{array}$ & $\begin{array}{l}\text { Limite } \\
\text { d }\end{array}$ & $x$ & $\begin{array}{l}\text { Demand } \\
\text { Driven } \\
\text { Demand }\end{array}$ & $x$ & $\checkmark$ & $\checkmark$ & $\checkmark$ & Limited & $\checkmark$ \\
\hline $\begin{array}{l}\text { CADR } \\
\text { COUGA }\end{array}$ & Flat & Low & $x$ & $\begin{array}{l}\text { d } \\
\text { Limite }\end{array}$ & No & $x$ & $\begin{array}{l}\text { Driven } \\
\text { Demand }\end{array}$ & $x$ & $x$ & $\sqrt{ }$ & $x$ & Limited & $x$ \\
\hline $\mathrm{R}$ & Flat & Low & $\sqrt{ }$ & d & $\begin{array}{l}\text { No } \\
\text { Very }\end{array}$ & $x$ & Driven & $x$ & $x$ & $\sqrt{ }$ & $x$ & Limited & $x$ \\
\hline RR [15] & $\begin{array}{l}\text { Flat } \\
\text { Hierarchic }\end{array}$ & Low & $\sqrt{ }$ & N/A & $\begin{array}{l}\text { Limite } \\
\text { d }\end{array}$ & $x$ & $\begin{array}{l}\text { Demand } \\
\text { Driven } \\
\text { Continuousl }\end{array}$ & $x$ & $x$ & $\checkmark$ & $x$ & Good & $x$ \\
\hline SOP [55] & & High & $x$ & Low & No & $\times$ & & $x$ & $x$ & $x$ & $\sqrt{ }$ & Limited & $x$ \\
\hline & & High & $x$ & Max & & $x$ & $\begin{array}{l}\text { Cluster } \\
\text { Head }\end{array}$ & $x$ & $x$ & $\sqrt{ }$ & $\checkmark$ & Good & $x$ \\
\hline $\begin{array}{l}\text { PEGASI } \\
\mathrm{S}\end{array}$ & $\begin{array}{l}\text { Hierarchic } \\
\text { al }\end{array}$ & High & $x$ & Max & $\begin{array}{l}\text { Fixed } \\
\text { Bs }\end{array}$ & $x$ & $\begin{array}{l}\text { Cluster } \\
\text { Head }\end{array}$ & $x$ & $x$ & $\times$ & $\checkmark$ & Good & $x$ \\
\hline $\begin{array}{l}\text { VGA } \\
\text { [55] } \\
\text { TEEN \& }\end{array}$ & $\begin{array}{l}\text { Hierarchic } \\
\text { al }\end{array}$ & High & $x$ & N/A & No & $x$ & $\begin{array}{l}\text { Continuousl } \\
\text { y }\end{array}$ & $x$ & $\checkmark$ & $\checkmark$ & $\checkmark$ & Good & $\checkmark$ \\
\hline $\begin{array}{l}\text { APTEEN } \\
{[17,18]}\end{array}$ & $\begin{array}{l}\text { Hierarchic } \\
\text { al }\end{array}$ & High & $x$ & $\begin{array}{l}\text { Max } \\
\text { Limite }\end{array}$ & $\begin{array}{l}\text { Fixed } \\
\text { Bs } \\
\text { Limite }\end{array}$ & $x$ & $\begin{array}{l}\text { Active } \\
\text { Threshold } \\
\text { Virtual }\end{array}$ & $x$ & $x$ & $\sqrt{ }$ & $\checkmark$ & Good & $x$ \\
\hline GAF [56] & Location & Mod & $x$ & d & d & $x$ & $\begin{array}{l}\text { Grid } \\
\text { Continuousl }\end{array}$ & $x$ & $\times$ & $x$ & $\times$ & Good & $x$ \\
\hline SAR & Location & High & $\sqrt{ }$ & N/A & No & $\sqrt{ }$ & $\begin{array}{l}\text { y } \\
\text { Demand }\end{array}$ & $x$ & $\sqrt{ }$ & $\sqrt{ }$ & $x$ & Limited & $x$ \\
\hline $\begin{array}{l}\text { MFR } \\
\text { SPAN }\end{array}$ & Location & High & $x$ & N/A & $\begin{array}{l}\text { No } \\
\text { Limite }\end{array}$ & $x$ & $\begin{array}{l}\text { Driven } \\
\text { Demand }\end{array}$ & $x$ & $x$ & $x$ & $x$ & Limited & $x$ \\
\hline $\begin{array}{l}{[19]} \\
\text { GEAR }\end{array}$ & Location & High & $x$ & $\begin{array}{l}\text { N/A } \\
\text { Limite }\end{array}$ & $\begin{array}{l}\mathrm{d} \\
\text { Limite }\end{array}$ & $x$ & $\begin{array}{l}\text { Driven } \\
\text { Demand }\end{array}$ & $x$ & $\sqrt{ }$ & $x$ & $x$ & Limited & $x$ \\
\hline [27] & Location & Mod & $x$ & d & & $\begin{array}{l}\times \\
\text { Lo }\end{array}$ & $\begin{array}{l}\text { Driven } \\
\text { Demand }\end{array}$ & $x$ & $x$ & $x$ & $x$ & Limited & $x$ \\
\hline GOAFR & Location & High & $\times$ & N/A & No & $\mathrm{w}$ & Driven & $x$ & $x$ & $x$ & $x$ & $x$ & $x$ \\
\hline
\end{tabular}

\section{Energy Efficient Routing Protocols in IoT}

In [42], M2M communication is a term which is related to technologies that enable both wired /wireless systems to transmit messages from one device to another device either in the homogeneous or heterogeneous network without any human intervention. At present wireless sensors are acting as primary building blocks of $\mathrm{M} 2 \mathrm{M}$ communication these topology is an dynamic nature. Machine devices process the events which are captured through nodes and transmitting through proper gateway. In M2M comunication battery power should ne used efficiently because some devices need to run for overtime, the energy depleted by sensor nodes possess both communication and computing energies. These two methods helps in minimizing the consumption of energy and increases the network lifetime through an proper topology and implements a sleep technique in a hierachical organization.
In [43], Wireless communication is developing day-today along with improvements in cheapest performance. The IoT evolved applications consists of self-organizations and collaboration between various wireless gadgets, whereas traditional wireless network services are does not meets requirements. At present most of the wireless networks are based on cellular and wireless local area networks which are almost point to point in nature and thus it can be able to provide communication amongst a mobile device and wired infrastructure. MANET is a self-organized communication with an infrastructure less, spontaneous and arbitrary multihop features which founds to be the suitable solution for particular scenarios. There are various challenges exist in MANET, for example every mobile node has limited range of communication, power supply is limited and because of node movements, there exists chances of link breakage. To transmit data in MANETS, they propose a novel protocol called Cooperative Relay Routing Protocol (CRRP) CRRP is a protocol which is used to locate the lack of systematic 
cooperative Relay Routing Scheme. Since, cooperative communication consumes less power, reduces interference and has potential diversity of channel; it gains more attention which triggers CRRP to consume less energy.

In [44], Some of the IoT devices has restricted their resources, to overcome these limitations, LOADng is developed which is a simple and basic version of AODV and it can be a substitute to standard RPL protocol. Various studies proved that, the popular IoT applications like, MP2P and $\mathrm{P} 2 \mathrm{P}$ which has applications RPL, consists of various drawbacks, thus the LOADng use becomes acceptable. The study of LOADng contains performance evaluation which is related to three metrics of network, which are taken as loss rate in packet, energy spent on per delivered bit and latency of end-to-end point.

In [45], IoT is becoming a trend of future in various aspects containing all kinds of smart objects such as home appliances, actuators, smartphones, sensors and RFID. Different kinds of wireless communication technologies are combined in IoT. The WSNs and WMN is one of the most booming configurations in IoT. WSN consists of set of small devices which routes the data to one or more sinks. In $\mathrm{WMN}$, to provide the connectivity, the nodes and networks communicates in a mess manner and WMN acts as a gateway for WSN and other smart objects and then it provides fast connectivity through the wireless medium and more bandwidth than short-range communication systems such as Bluetooth and Zigbee. With the help of resources like, cellular, WiFi and the internet the router of WMN connects to other requested clients and routers. WMN has multi-hop nature its architecture is decentralized and composed of communicated and distributed nodes.

In [46], author proposed new algorithm called Distributed Monitoring Architecture (DMoA). The main purpose of using this architecture is monitoring the network based on RPL protocol. DMoA contains regular nodes which are used in small devices which are capable into $\mathrm{C} 0$ or $\mathrm{C} 1$ class of constrained devices. Regular nodes is mainly used to perform sensing from source to destination and performs some actions. The nodes will interact in multihop fashion in order to avoid the faults occurred due to link breakage or node failures. Second type node called as monitoring nodes, which are used in large devices which are partially $\mathrm{C} 2$ class. Monitoring nodes are inactively listening from regular nodes and store vital information and forwards to sink. Monitoring nodes contains high bandwidth compare to regular nodes.

In [47], author proposed MSGR (Mode Switched Grid based Routing) protocol. The advantage of using MSGR is to minimize the overhead in network. In MSGR, very less nodes will changed due to random destination flow has limited impact. This protocol contains Grid Heads $(\mathrm{GH})$ which will select only one node in a grid. GH will establish connection between source to sink node. GH are convert from active mode to sleep mode. The advantage of GH is low energy consumption and increasing the lifetime of the network.
In [48], author proposed Xbee which will identify neighbor nodes and assign unique address and performs routing from source to destination. Xbee is exist in link layer and network layer which are pervasive in nature. This will avoid the collision, routing and dynamic addressing in these two layers. The service discovery is exist in application layer and the protocols are Bonjour, UPnP and Alljoyn. Advantages of Xbee is addressing, reliable, collision avoidance and fast. The new protocol are implemented between smart nodes and smart gateways are used in application layer. Xbee router will perform as smart nodes and smart gateway will act as Xbee coordinator.

In [49], author proposed new protocol called queue utilization based RPL (QU-RPL). This is used to control load balancing and avoid congestion in network. In this every node to chosen its root node based on neighbor nodes and hop distances. QU-RPL significantly improves packet delivery ratio. Objective functions (OFs) is used to select routes and provide optimize routes in RPL routing topology. To calculate path and selection of root based upon hop count or ETX. The advantage of QU-RPL is minimal packet loss, performance and network lifetime is increased.

In [50], Neighbor Unreachable Detection (NUD) is used in RPL. The implementation in NUD contains two types such as hello packet and DIO messages. In this algorithm parent node will form in DODAG or DIO message to all nodes in a network. Trickle algorithm is used to generate the DIO messages. DIO message contains ranks based on OF, and performs optimization based on selected routes. If node receives more than one DIO messages from neighbor nodes then it will selects least rank, afterwards it will forward the updated DIO message to all nodes in a network. RPL construct the routes in two approaches such as upward direction and downward direction. NUD is used to find out link failure in a network. Every node must maintain localization of nodes in a network. If a node receive positive acknowledgement from neighbor nodes then it says the node is reachable. If a node not receiving any acknowledgment within stipulated time then the node is goes to Stale.

In [51], author proposed Multimedia IoT (IoMT). The aim use of IoMT is to provide optimize solution for IoT based on combining various models into single model. Based on various criteria, the IoT applications can used multiple objectives. In IoMT, contains 3 layer approach such as physical layer, link layer and network layer. In physical layer, channel and modulations are used. In link layer, it deals with packet error from end to end and security. In network layer it performs routing from source to destination. IoMT objects consists of heterogeneity devices which providing fault tolerance and secure between source to sink with less energy consumption. To overcome issue of optimization multiobective function is used in IoMT.

The various existing algorithms, simulation environments, and its parameters are illustrated in given table 3 .

Table 3. Summary of existing algorithms in IoT environment.

\begin{tabular}{|c|c|c|c|}
\hline Author & Algorithm & Advantages & Simulator \\
\hline $\begin{array}{l}\text { Shaker Alanazi et } \\
\text { al. (2015) }\end{array}$ & Wireless Mesh Network (WMN) [45] & 1. It is more securable & NS-2 and OMNET++ \\
\hline $\begin{array}{l}\text { Bilal R. } \\
\begin{array}{l}\text { Kaseem } \\
(2016)\end{array}\end{array}$ & SEE -M2M [42] & $\begin{array}{l}\text { 1. Network lifetime is increased } \\
\text { 2. High packet delivery to base } \\
\text { station }\end{array}$ & MATLAB \\
\hline
\end{tabular}


Jingwen Bai et al. (2016)

Jose V. V. Sobral et al. (2016)

Al-Kaseem et al. (2016)

Sabriansyah Rizqika Akbar et al. (2016)

Hyung-Sin Kim et al. (2016)

Lapas Pradittasnee (2016)

Chiu et al. (2016)

Kbir et al. (2016)

Qin Luo (2017)

Sha (2017)
Cooperative Relay Routing Protocol (CRRP) [43]

LOADng[44]

SOC-M2M [26]

XBee [48]

Queue Utilization based RPL (QURPL) [49]

Neighbor Unreachable Detection (NUD) [50]

Software defined networking architecture [51]

Wireless Multimedia Sensor

Network (WMSN) [54]

Multiple QoS Parameters based Routing Protocol (MQSPR) [52]

Wireless Highway Addressable

Remote Transducer Protocol (Wireless HART) [53]
1. Performance is very high

2. High Throughput

3. Fault Tolerance

1. Performance is very high

1. Network lifetime is increased

2. High packet delivery to base station

1. It is more securable

1. Performance is very high

2. Low packet loss

3. High packet delivery to base station

1. High packet delivery to base station

1. Performance is very high

1. Performance is very high

2. High packet delivery to base station

1. Performance is very high

2. High packet delivery to base station

3.Stability and load balancing

1. Low energy consumption

2. Network reliability will be high
OPNET

CASTALIA

MATLAB

ARDUINO UNO and RASPBERRY PI

TINYRPL

CONTIKI OS

NS3

CASTALIA

NS2.35

TINYOS 2.1.2 and TELOSB MOTES

\section{Conclusion}

In this Survey paper, we have discussed the challenges in routing protocols and categorize them based on network structure, method of route discovery and method of protocol operations. The common agenda of all these routing protocols is to reduce the energy consumption of sensor nodes. In contrast, flat based routing is best for small networks. Rumor routing is having the advantage of the scalability and low overhead in the flat routing protocol. The hierarchical routing protocol is capable of handling more number of sensor nodes with an efficient communication between them. In hierarchical routing, the data aggregation is performed to reduce energy consumption by minimizing the number of messages between sensor nodes. The above discussed routing protocols help in estimating energy consumption between nodes by acquiring location information of sensor nodes. In our findings we state that hierarchical based routing is best for large networks as it provides good scalability. In our review we found that Matlab and Contiki OS are widely used simulators in the area of IoT.

Access article distributed under the terms of the Creative Commons Attribution Licence

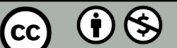

1. Money INTERNET, Available http://time.com/money/3896219/internet-users-worldwide/, accessed May 2015.

2. G Kortuem, F Kawsar, V Sundramoorthy, D Fitton. Smart objects as building blocks for the internet of things. IEEE Internet Computing. 2010; 14(1), 44-51.

3. K Ashton. That 'internet of things' thing. RFiD Journal. 2009; 22(7), 97-114

4. A Whitmore, A Agarwal, L Da Xu. The Internet of Things-A survey of topics and trends. Information Systems Frontiers. 2015; 17(2), 261-74.

5. K Zhao, L Ge. A survey on the internet of things security. InComputational Intelligence and Security (CIS). 2013; 663-667.

6. Gartner Newsroom, Available at: http://www.gartner.com/newsroom/id/3165317, accessed November 2015.

\section{References}

8
7. Cisco Blogs, Available at: http://blogs.cisco.com/news/cisco-
connections-counter, accessed July 2013 .

8. K Rose, S Eldridge, L Chapin. The internet of things: An overview. The Internet Society (ISOC). 2015; 1-50.

9. P Sethia, SR Sarangi, Internet of Things: Architectures, Protocols, and Applications. Journal of Electrical and Computer Engineering. 2017, DOI: org/10.1155/2017/9324035.

10. A Dhumane, R Prasad, J Prasad. Routing Issues in Internet of Things: A Survey. InProceedings of the International MultiConference of Engineers and Computer Scientists. 2016; Vol. 1, 16-18.

11. K Machado, D Rosário, E Cerqueira, AA Loureiro, A Neto, JN de Souza. A routing protocol based on energy and link quality for internet of things applications. sensors. 2013; 13(2), 1942-64.

12. C Kharkongor, T Chithralekha, R Varghese. A SDN Controller with Energy Efficient Routing in the Internet of Things (IoT). Procedia Computer Science. 2016; 89, 218-27. 
13. WR Heinzelman, J Kulik, H Balakrishnan. Adaptive protocols for information dissemination in wireless sensor networks. InProceedings of the 5th annual ACM/IEEE international conference on Mobile computing and networking. 1999; 174-185.

14. C Intanagonwiwat, R Govindan, D Estrin. Directed diffusion: A scalable and robust communication paradigm for sensor networks. InProceedings of the 6th annual international conference on Mobile computing and networking. 2000; 56-67.

15. D Braginsky, D Estrin. Rumor routing algorthim for sensor networks. InProceedings of the 1st ACM international workshop on Wireless sensor networks and applications. 2002; 22-31.

16. F Ye, A Chen, S Lu, L Zhang. A scalable solution to minimum cost forwarding in large sensor networks. InComputer Communications and Networks. 2001; 304-309.

17. A Manjeshwar, DP Agrawal. TEEN: ARouting Protocol for Enhanced Efficiency in Wireless Sensor Networks. Inipdps. 2001; Vol. 1, 189.

18. A Manjeshwar, DP Agrawal. APTEEN: A Hybrid Protocol for Efficient Routing and Comprehensive Information Retrieval in Wireless Sensor Networks. InIpdps. 2002; Vol. 2, 48.

19. B Chen, K Jamieson, H Balakrishnan, R Morris. Span: An energyefficient coordination algorithm for topology maintenance in ad hoc wireless networks. Wireless networks. 2002; 8(5), 481-94.

20. L Carr-Motyčková, D Dryml. Distributed energy efficient data gathering without aggregation via spanning tree optimization. InInternational Conference on Ad-Hoc Networks and Wireless. 2013; 87-98.

21. T Qiu, X Liu, L Feng, Y Zhou, K Zheng. An efficient tree-based self-organizing protocol for internet of things. IEEE Access. 2016; 4, 3535-46.

22. A Roshini, H Anandakumar. Hierarchical cost effective leach for heterogeneous wireless sensor networks. InAdvanced Computing and Communication Systems. 2015; 1-7.

23. V Sharma, DS Saini. Performance Investigation of Advanced Multi-Hop and Single-Hop Energy Efficient LEACH Protocol with Heterogeneous Nodes in Wireless Sensor Networks. InAdvances in Computing and Communication Engineering (ICACCE). 2015; 192-197.

24. AA Malluh, KM Elleithy, Z Qawaqneh, RJ Mstafa, A Alanazi. Emsep: an efficient modified stable election protocol. InAmerican Society for Engineering Education (ASEE Zone 1). 2014; 1-7.

25. T Tiwari, NR Roy. Modified DEEC: A varying power level based clustering technique for WSNs. InComputer and Computational Sciences (ICCCS). 2015; 170-176.

26. BR Al-Kaseem, AO Nyanteh, HS Al-Raweshidy. Self-Organized Clustering technique based on sink mobility in heterogeneous M2M sensor networks. InStudents on Applied Engineering (ISCAE). 2016; 431-436.

27. $\mathrm{Y} \mathrm{Yu}, \mathrm{R}$ Govindan, D Estrin. Geographical and energy aware routing: A recursive data dissemination protocol for wireless sensor networks. Springer. 2001; 211-221.

28. VB Carvalho. 2010, Including context in a routing algorithm for the Internet of Things, Doctoral Dissertation. Faculdade de Ciências e Tecnologia, Lisboa, Portugal.

29. G Di Caro, F Ducatelle, LM Gambardella. AntHocNet: an adaptive nature-inspired algorithm for routing in mobile ad hoc networks. European Transactions on Telecommunications. 2005; 16(5), 443 55.

30. F Dressler, OB Akan. A survey on bio-inspired networking. Computer Networks. 2010; 54(6), 881-900.

31. M Farooq, GA Di Caro. Routing protocols for next-generation networks inspired by collective behaviors of insect societies: An overview. Springer. 2008; 101-160.

32. IETF, Available at: http://www.ietf.org proceedings/82/slides/rtgarea-2.pdf?, accessed November 2011.

33. GC Onwubolu, BV Babu. New optimization techniques in engineering. 1st ed. Springer-Verlag Berlin Heidelberg; 2013, p. 12 .

34. C Lochert, M Mauve, H Füßler, H Hartenstein. Geographic routing in city scenarios. ACM SIGMOBILE mobile computing and communications review. 2005; 9(1), 69-72.

35. Y Tian, R Hou. An improved AOMDV routing protocol for internet of things. InComputational Intelligence and Software Engineering (CiSE). 2010; 1-4.

36. CE Perkins, $\mathrm{P}$ Bhagwat. Highly dynamic destination-sequenced distance-vector routing (DSDV) for mobile computers. InACM SIGCOMM computer communication review. 1994; 24(4), 234-244.
37. O Younis, S Fahmy. Distributed clustering in ad-hoc sensor networks: A hybrid, energy-efficient approach. InINFOCOM 2004. Twenty-third AnnualJoint Conference of the IEEE Computer and Communications Societies. 2004; 1.

38. WB Heinzelman, AP Chandrakasan, $H$ Balakrishnan. An application-specific protocol architecture for wireless microsensor networks. IEEE Transactions on wireless communications. 2002; 1(4), 660-70.

39. AK Kaushik. Performance Evaluation of Proactive and Reactive Routing Protocols in Wireless Sensor Networks. International Journal of Computer Applications. 2015; 110(16).

40. MJ Handy, M Haase, D Timmermann. Low energy adaptive clustering hierarchy with deterministic cluster-head selection. InMobile and Wireless Communications Network. 2002; 368-372.

41. WR Heinzelman, A Chandrakasan, H Balakrishnan. Energyefficient communication protocol for wireless microsensor networks. InSystem sciences, Proceedings of the 33rd annual Hawaii international conference. 2000; 1-10.

42. BR Al-Kaseem, HS Al-Raweshidy. Scalable M2M routing protocol for energy efficient IoT wireless applications. InComputer Science and Electronic Engineering (CEEC).2016; 30-35.

43. J Bai, Y Sun, C Phillips. CRRP: A cooperative relay routing protocol for IoT networks. InPersonal, Indoor, and Mobile Radio Communications (PIMRC). 2016; 1-6.

44. JV Sobral, JJ Rodrigues, K Saleem, J Al-Muhtadi. Performance evaluation of LOADng routing protocol in IoT P2P and MP2P applications. InComputer and Energy Science (SpliTech), International Multidisciplinary Conference. 2016; 1-6.

45. S Alanazi, J Al-Muhtadi, A Derhab, K Saleem, AN AlRomi, HS Alholaibah, JJ Rodrigues. On resilience of Wireless Mesh routing protocol against DoS attacks in IoT-based ambient assisted living applications. InE-health Networking, Application \& Services (HealthCom). 2015; 205-210.

46. A Mayzaud, A Sehgal, R Badonnel, I Chrisment, J Schönwälder. Using the RPL protocol for supporting passive monitoring in the Internet of Things. InNetwork Operations and Management Symposium (NOMS). 2016; 366-374.

47. S. Sharma, D. Puthal, S. Tazeen, M. Prasad and A. Y. Zomaya, "MSGR: A Mode-Switched Grid-based Sustainable Routing Protocol for Wireless Sensor Networks," in IEEE Access, vol. PP, no. 99, pp. 1-1SR Akbar, W Kurniawan, MH Ichsan, I Arwani, MT Handono. Pervasive device and service discovery protocol in XBee sensor network. InAdvanced Computer Science and Information Systems (ICACSIS). 2016; 79-84.

48. Akbar, Sabriansyah Rizqika, Wijaya Kurniawan, Mochammad Hannats Hanafi Ichsan, Issa Arwani, and Maystya Tri Handono. "Pervasive device and service discovery protocol in XBee sensor network." In Advanced Computer Science and Information Systems (ICACSIS), 2016 International Conference on, pp. 79-84. IEEE, 2016.

49. HS Kim, H Kim, J Paek, S Bahk. Load Balancing under Heavy Traffic in RPL Routing Protocol for Low Power and Lossy Networks. IEEE Transactions on Mobile Computing. 2016; 964979.

50. L Pradittasnee. A study of the neighbor unreachability detection mechanism to improve performance of RPL protocol. InInformation Technology and Electrical Engineering (ICITEE). 2016; 1-6.

51. JC Chiu, AT Liu, CC Liao. Design the DNS-Like Smart Switch for Heterogeneous Network Base on SDN Architecture. InComputer Symposium (ICS). 2016; 187-191.

52. Rani, S., Ahmed, S. H., Talwar, R., Malhotra, J., \& Song, H. (2017). IoMT: A Reliable Cross Layer Protocol for Internet of Multimedia Things. IEEE Internet of Things Journal.

53. M Sha, D Gunatilaka, C Wu, C Lu. Empirical Study and Enhancements of Industrial Wireless Sensor-Actuator Network Protocols. IEEE Internet of Things Journal. 2017; 99, 1-8.

54. MA Kbir, M Bennani. Round time adaptation for image transfering over wireless sensor networks leach protocol. InInformation Science and Technology (CiSt). 2016;896-900.

55. L Subramanian, RH Katz. An architecture for building selfconfigurable systems. InProceedings of the 1st ACM international symposium on Mobile ad hoc networking \& computing. 2000; 6373.

56. Y Xu, J Heidemann, D Estrin. Geography-informed energy conservation for ad hoc routing. InProceedings of the 7th annual international conference on Mobile computing and networking. 2001; 70-84 
57. B Bellur, RG Ogier. A reliable, efficient topology broadcast protocol for dynamic networks. InINFOCOM'99. Eighteenth Annual Joint Conference of the IEEE Computer and Communications Societies. Proceedings. 1999; 1, 178-186.

58. GP Hancke, CJ Leuschner. SEER: a simple energy efficient routing protocol for wireless sensor networks. South African Computer Journal. 2007; 2007(39), 17-24.

59. C Perkins, E Belding-Royer, S Das. Ad hoc on-demand distance vector (AODV) routing. 2003; 1-37.
60. B Karp, HT Kung. GPSR: Greedy perimeter stateless routing for wireless networks. InProceedings of the 6th annual international conference on Mobile computing and networking. 2000; 243-254.

61. ZJ Haas, MR Pearlman. The performance of query control schemes for the zone routing protocol. IEEE/ACM Transactions on Networking (TON). 2001; 9(4), 427-38.

62. P Jacquet, P Muhlethaler, T Clausen, A Laouiti, A Qayyum, L Viennot. Optimized link state routing protocol for ad hoc networks. InMulti Topic Conference. 2001; 62-68. 